\title{
ORGANIZAÇÕES SOCIAIS E EDUCAÇÃO: PERFIS E TENDÊNCIAS EM MARCOS LEGAIS NORDESTINOS
}

\author{
Ariane Silva ${ }^{1}$ \\ Zara Figueiredo Tripodi ${ }^{2}$
}

\begin{abstract}
RESUMO: Apresentam-se resultados da pesquisa que investigou os marcos legais de Organizações Sociais (OS) na educação básica em estados nordestinos. A partir da revisão de literatura, foram construídas três categorias que permitiram enquadrar analiticamente o debate sobre OS na educação: 1) possibilidade de oferta; 2) gratuidade; 3) cessão de servidor público. O estudo permite afirmar que: 1) a possibilidade de oferta de educação está positivada em todas as leis estaduais do nordeste; 2) à exceção de Pernambuco, todos os textos silenciam sobre a gratuidade da educação, se ofertada por OS; 3 ) os entes analisados, exceto Ceará, preveem a possibilidade de cessão de servidor. Por fim, foram encontradas leis que normatizam transferência de encargos previdenciários de servidores a OS via orçamento.
\end{abstract}

Palavras-chave: Política educacional. Organizações sociais. Privatização da educação. Legislação estadual.

\section{SOCIAL ORGANIZATIONS AND EDUCATION: PROFILES AND TRENDS IN NORTHEASTERN LEGAL MARKS}

\begin{abstract}
We present here the results of a research investigating the legal framework of Social Organizations (SO) in the basic education of Brazilian Northeastern states. From a literature review, three categories were created to allow the analytical framing of the debate about the presence of SO in education: 1) opportunity for offer; 2) gratuity; and 3) assignment of government employee. The study allows us to state that: 1) the possibility to offer education is established in all the state laws of the Brazilian Northeast Region; 2) with the exception of Pernambuco, all texts are silent about gratuity of education once offered by SO; 3 ) the entities analyzed, with exception of Ceará, provide for the possibility of assigning government employees in the legislation. Finally, it was observed that some laws provide for the transfer of social security charges of government employees to SO through budget.
\end{abstract}

Keywords: Educational policy. Social organizations. Education privatization. State legislation.

O trabalho vincula-se ao projeto de pesquisa "Fronteiras do Estado na Educação: Características, Condicionantes e Tendências de Privatização" e contou com o financiamento da FAPEMIG, por meio de bolsa de pesquisa, no âmbito do Convênio 5246/15.

1.Universidade Federal de Ouro Preto - Núcleo de Estudos e Pesquisas em Políticas Públicas de Educação - Ouro Preto (MG), Brasil. E-mail: arianedianes@gmail.com

2.Universidade Federal de Ouro Preto - Núcleo de Estudos e Pesquisas em Políticas Públicas de Educação - Ouro Preto (MG), Brasil. E-mail: zarafigueiredo@gmail.com

Editor de Seção: Salomão Barros Ximenes 


\section{ORGANIZACIONES SOCIALES Y EDUCACIÓN: PERFILES Y TENDENCIAS EN MARCOS LEGALES NORDESTINOS}

RESUMEN: El texto presenta resultados de una investigación que analiza los marcos legales de las Organizaciones Sociales (OS) en la educación básica desde las provincias del noreste brasileño. Por medio de una revisión de la literatura se construyeron tres categorías que permitieron enmarcar analíticamente el debate sobre la presencia de las Organizaciones Sociales en la educación: 1) posibilidad de oferta; 2) gratuidad de la educación; y3) concesión de servidores públicos. El estudio permite afirmar que 1) la posibilidad de ofrecer educación es positiva en todas las leyes de las provincias del noreste; 2) con la excepción de Pernambuco, todos los textos guardan silencio sobre la gratuidad de la educación, si es ofrecida por una Organización Social; y 3) de las provincias analizadas, excepto Ceará, la legislación ofrece la posibilidad de cesión de funcionario público. Por último, se han observado leyes que prevén la transferencia de costos de seguridad social de los funcionarios públicos a las Organizaciones Sociales por medio del presupuesto público.

Palabras-clave: Políticas educativas. Organizaciones Sociales. Privatización de la educación. Legislación estatal.

\section{Introdução}

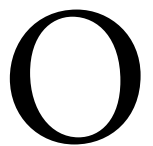

debate em torno da constituição, da atuação e da legitimidade das Organizações da Sociedade Civil (OSC) é ainda objeto de muita controvérsia no meio acadêmico, como bem evidenciam os trabalhos de Avritzer (2012), Lavalle (2015) e Gohn (2000). Um dos elementos relacionados à dificuldade de consenso em torno dessas organizações diz respeito à própria constituição do chamado terceiro setor, que enfeixa um conjunto de entidades muito diferentes entre si, com finalidades distintas, diferentes níveis de sustentabilidade financeira e modos de atuação diversos. Nesse sentido, a análise em torno de Organizações Sociais (OS), Organizações da Sociedade Civil de Interesse Público (OSCIP) e outras modalidades de OSC não prescinde de que se considere a morfologia institucional de cada uma delas, o que demanda, do ponto de vista da pesquisa, certa parcimônia teórica e metodológica, sobretudo no exame de seus efeitos.

No caso das OS, chama a atenção, de plano, a própria definição dessas entidades, pelo potencial de se traduzirem em estratégias de privatização, em que pese o discurso oficial à época, mas também na atualidade, como bem apontam Stuchi et al. (2020), ao examinarem o Programa "Future-se", no âmbito do Ensino Superior.

As OS foram definidas pelo Ministério da Administração e Reforma do Aparelho de Estado (MARE) como "um modelo de organização pública não estatal destinado a absorver atividades publicizáveis mediante qualificação específica”, sendo constituída por associações civis sem fins lucrativos e orientadas para o atendimento do interesse público (BRASIL, 1998, p. 13).

A partir dos anos de 1990, as OS passaram a ser consideradas por importantes atores do MARE como uma privilegiada ferramenta de produção de políticas sociais, por supostamente superar os limites de Estado e mercado. A proposta foi normatizada no âmbito federal pela Lei n. 9.637/1998, mas o MARE não conseguiu o apoio político necessário à época para sua implementação, especialmente no que tange às universidades federais, como se buscava fazer. Todavia, se o projeto não foi exitoso na esfera federal, o marco legal tornou-se um importante instrumento indutor de produção normativa no âmbito estadual. 
O presente trabalho deriva desse debate, examinando a legislação estadual de OS de modo a compreender qual o seu alcance para a área educacional. Afinal, como bem pontua Donnini (2017), o caráter minimalista da Lei Federal n. 9637/1998, no tocante à contratação de OS, deixa um significativo espaço discricionário para os entes federados definirem contornos próprios.

Busca-se, assim, investigar quais as tendências expressas nesses documentos para a educação básica em termos de oferta, modos de provisão e possibilidade de cessão de servidor público. Em outros termos, busca-se saber se, na legislação estadual, está prevista a atuação de OS em áreas finalísticas, como atividades de ensino, ou apenas em atividades-meio, relacionadas a aspectos administrativos, como apontaram os achados de pesquisa de Vilella e Donnini (2018) ao examinarem as primeiras etapas de implementação da interação do estado da Paraíba com OS na educação.

A escolha intencional pelos estados do Nordeste justifica-se pelo fato de que boa parte deles já ultrapassou o gasto de pessoal permitido pela Lei de Responsabilidade Fiscal, segundo a Firjan (IFDM, 2017), e, portanto, seria possível pensar na utilização de OS como forma de abrir espaço fiscal, à medida que se diminuísse o peso com folha de pagamento do Estado.

Além dessa introdução, o trabalho traz, na sequência, as notas metodológicas que conduziram a pesquisa, para, em seguida, tratar dos contornos do marco legal que regra juridicamente as OS no âmbito federal, da qual decorrem os textos estaduais, pelo menos em termos de temática, podendo o conteúdo substantivo divergir daquele da União. Na seção subsequente, faz-se uma breve sistematização do debate em torno das OS na esfera da educação básica, debate esse apontado pelas pesquisas, para, então, serem apresentados os dados e sua discussão. As conclusões vêm logo após.

\section{Notas Metodológicas}

O estudo qualitativo contou, na sua primeira etapa, com uma revisão da literatura sobre os conceitos Organizações da Sociedade Civil, terceiro setor e Nova Gestão Pública. Ainda nessa fase, foi feita uma pesquisa no Banco de Dissertação e Teses da Capes, a fim de selecionar e revisar as pesquisas que investigaram a presença de OS na educação.

A partir daí, foram construídas três categorias, que enquadraram analiticamente os marcos legais levantados: 1) oferta educacional; 2) modo/gratuidade da oferta; e 3) recursos humanos/cessão de servidor público para OS. Em seguida, foi realizada uma extensa pesquisa documental nos sítios das assembleias estaduais, de modo a construir um banco de dados com os textos legais selecionados, que foram tratados e sistematizados na etapa posterior. Por fim, procedeu-se à análise, tendo a literatura selecionada guiado o trabalho interpretativo.

\section{A Lei Federal de OS}

Inicialmente, cabe sublinhar que não existem, a rigor, Organizações Sociais, no sentido de já se instituírem como tal desde a criação. Na verdade, elas representam uma das muitas entidades que constituem o denominado terceiro setor e que, por meio de um processo de qualificação, recebem ou não o título de OS do Executivo, podendo ser federal, estadual ou municipal. É nessa direção que Modesto afirma que "nenhuma entidade é constituída como organização social" e que, portanto, "ser organização social não se pode traduzir em uma qualidade inata, mas em uma qualidade adquirida, resultado de um ato formal de reconhecimento 
do Poder Público, facultativo e eventual, semelhante em muitos aspectos à qualificação deferida às instituições privadas sem fins lucrativos quando recebem o título de utilidade pública” (1998, p. 8).

O segundo aspecto digno de nota é que a definição dada às OS precisa ser pensada na sua articulação com a própria concepção que subsidiava a reforma de Estado dos anos 1990, de reduzir o tamanho do Estado social. Com isso, quer-se dizer que as OS não constituem atividade de fomento, como as OSCIP. Antes, o seu desenho "é destinado a absorver atividades públicas", sendo construída como instrumento jurídico de privatização de serviços públicos, tal qual acertadamente afirma Di Pietro (2015).

O Plano Diretor de Reforma do Aparelho de Estado (PDRAE), no âmbito desse debate, pode ser entendido como um importante instrumento, na medida em que representa, de um lado, o marco conceitual do "lugar" das OS na redução do tamanho do Estado e, de outro, uma ferramenta política, uma vez que as ideias ali contidas foram aglutinadas e difundidas pelos fautores do projeto reformista, de modo a sustentar o marco legal dessas entidades, o qual viria a ser aprovado.

Assim sendo, o passo seguinte ao PDRAE foi o envio de Proposta de Emenda Constitucional e Projetos de Lei ao Congresso Nacional, a fim de que alterassem a estrutura legal da administração pública, considerada pelos defensores do gerencialismo como ultrapassada, ineficiente e engessada.

Entre o marco legal produzido, a Lei Federal n. 9.637, de 1998, e a Emenda Constitucional n. 19, do mesmo ano, parecem apresentar significativo potencial de redução do tamanho do Estado social, por meio da normatização de possibilidade de oferta de políticas públicas por meio de OS, mas, também, via alteração no desenho constitucional da administração pública, introduzindo a figura jurídica do contrato de gestão e do pagamento por performance, intimamente ligados e necessários à sustentação de interações socioestatais.

A qualificação de entidades como OS e a criação de Programa Nacional de Publicização estão no centro da formulação do marco legal, que, logo no seu art. $1^{\circ}$, prevê constituição, composição, finalidades e área de atuação, aspectos entre os quais se situam o ensino e a pesquisa.

A interação dos atores estatais com essas entidades estrutura-se, no plano legal, por meio de contratos de gestão, os quais cumpririam a função de prever as estratégias gerenciais que pautariam a lógica de gestão das OS, assim como definir os critérios de avaliação de desempenho a serem utilizados, mediante indicadores de qualidade e produtividade, como disposto no art. $7^{\circ}$.

Os aspectos mais controversos da Lei n. 9637/1998 são, todavia, aqueles referentes à sustentabilidade financeira dessas entidades, à possibilidade prevista em lei de transferência de servidor público estável e à cessão de infraestrutura para OS com contratos de gestão firmados com o Estado.

Uma vez qualificadas como OS, o art. 11 prevê que essas entidades sejam declaradas como de interesse social, passando a contar com recursos orçamentários e bens públicos necessários ao cumprimento do contrato de gestão (art. 12), incluindo aí crédito orçamentário adicional, de modo a compensar o desligamento de servidor cedido $\left(\$ 2^{\mathrm{a}}\right)$. Os bens públicos podem ser transferidos e, nesse caso, a lei prevê a dispensa de licitação, como forma de flexibilizar a gestão e, teoricamente, produzir resposta mais rápida, em termos de oferta de serviços, a par dos preceitos da administração gerencial. $\left(\$ 3^{\circ}\right)$.

A lei federal prevê, ainda, no artigo 14, a possibilidade de o servidor ser transferido para OS. No entanto, eventuais vantagens recebidas nessa esfera, decorrentes de incentivos, por exemplo, não podem ser incorporadas ao salário do servidor, tampouco serem decorrentes de orçamento recebido do Estado (art. 14).

Já o art. 22 regra juridicamente a possibilidade de absorção, por uma OS, de atividades e serviços públicos, de modo definitivo, o que constitui, como já se anunciou, atividade de privatização entendida no seu sentido estrito.

Embora possa se afirmar que o Governo Federal tenha sido exitoso em compor um ministério exclusivo para se projetar a reforma, desenhar o PDRAE, aprovar a Lei Federal n. 9.637/1998 e conseguir 
articular uma base governamental para aprovar a Emenda Constitucional n. 19/1998, o projeto reformista encontrou obstáculos políticos para ser implementado no âmbito federal. A aprovação do Programa Nacional de Publicização, por meio do Decreto n. 9.190/2017, regulamentando o disposto no artigo 20 da Lei n. 9.637, de 1998, só veio a ser efetivado em 2017, no governo do ex-Presidente Michel Temer (2016-2018).

De todo modo, ainda que as OS não tenham sido implementadas nas diversas áreas de políticas sociais, no âmbito federal, conforme se pretendia, o aprendizado da política levou a que os entes estaduais criassem seus próprios marcos legais, como se pode depreender da Tabela 1, sendo que alguns estados o fizeram mesmo antes da aprovação da lei federal, valendo-se, portanto, da Medida Provisória n. 1.648/1998, em vigor àquela altura.

Tabela 1. Marcos legais de OS nos Estados brasileiros e no Distrito Federal

\begin{tabular}{|c|c|}
\hline Estado & Organizações sociais (OS) \\
\hline Alagoas (AL) & Lei n. 7.777, de 22 de janeiro de 2016 \\
\hline Bahia (BA) & Lei n. 8.647, de 29 de julho de 2003 \\
\hline Ceará (CE) & Lei n. 12.781, de 30 de dezembro de 1997 \\
\hline Maranhão (MA) & Lei n. 7.066, de 3 de fevereiro de 1998 \\
\hline Paraíba (PB) & Lei n. 9.454, de 6 de outubro de 2011 \\
\hline Pernambuco (PE) & Lei n. 11.743 , de 20 de janeiro de 2000 \\
\hline Piauí (PI) & Lei Ordinária n. 5.519 de 13 de dezembro de 2005 \\
\hline Rio Grande do Norte (RN) & $\begin{array}{l}\text { Lei complementar n. 271, de } 26 \text { de fevereiro de } 2004 \\
\text { Lei complementar n. 468, de } 22 \text { de junho de } 2012 .\end{array}$ \\
\hline Sergipe (SE) & Lei n. 5.217, de 15 de dezembro de 2003 \\
\hline Acre $(\mathrm{AC})$ & - \\
\hline Amapá (AP) & Lei n. 0599, de 25 de abril de 2001 \\
\hline Amazonas (AM) & Lei n. 3.900, de 12 de julho de 2013 \\
\hline Pará (PA) & Lei n. 5.980, de 19 de julho de 1996 \\
\hline Rondônia (RO) & Lei n. 3.122, de 1 de julho de 2013 \\
\hline Roraima (RR) & - \\
\hline Tocantins (TO) & Lei n. 2.472, de 7 de julho de 2011 \\
\hline Distrito Federal (DF) & Lei n. 4.081 , de 4 de janeiro de 2008 \\
\hline Goiás (GO) & Lei n. 15.503 , de 28 de dezembro de 2005 \\
\hline Mato Grosso (MT) & Lei Complementar n. 150, de 8 de janeiro de 2004 \\
\hline Mato Grosso do Sul (MS) & Lei n. 4.698, de 20 de julho de 2015 \\
\hline Espírito Santo (ES) & Lei Complementar n. 489, de 21 de julho de 2009 \\
\hline Minas Gerais (MG) & Lei n. 23.081, de 10 de agosto de 2018 \\
\hline Rio de Janeiro (RJ) & Lei n. 5.498, de 7 de julho de 2009 \\
\hline São Paulo (SP) & Lei Complementar n. 846, de 4 de junho de 1998 \\
\hline Paraná (PR) & Lei Complementar n. 140, de 14 de dezembro de 2011 \\
\hline Rio Grande do Sul (RS) & Projeto de Lei n. 44/2016 \\
\hline Santa Catarina (SC) & Lei n. 12.901 , de 11 de janeiro de 2008 \\
\hline
\end{tabular}

Fonte: Elaboração própria com dados da pesquisa.

Atualmente, 24 estados brasileiros e o Distrito Federal possuem programas de publicização, nos quais está prevista a qualificação de entidades como OS. Apenas os estados de Roraima e Acre não possuem, 
embora esse último tenha aprovado a Lei Estadual n. 1.428, de 2 de janeiro de 2002, que regra juridicamente termos de parceria entre o estado e OSCIP.

\section{Organizações Sociais e Educação Básica}

A possibilidade de atuação de OS no âmbito educacional pode ser pensada a partir de três ordens de razões. Uma delas, de natureza financeira, refere-se aos recursos necessários para fazer face ao direito à educação e às políticas daí decorrentes, positivadas na Carta de 1988 (OLIVEIRA; ADRIÃO, 2013); uma segunda razão, de conteúdo político, diz respeito à opção de se manter uma estrutura tributária regressiva, com poucas possibilidades de financiar um Estado social que se delineava (GOBETTI; ORAIR, 2016); uma terceira razão, de natureza ideológica, orienta-se pela premissa da superioridade do terceiro setor em ganhos de eficiência e melhoria do controle social dos produtos oferecidos à sociedade (BRESSER-PEREIRA; GRAU, 1999).

É sobre esse plano de fundo que se erigem as OS como atores privilegiados para oferta educacional, básica ou superior, por supostamente superar dilemas que envolveriam os limites do Estado e do Mercado como produtores de serviços sociais.

Embora o PDRAE (BRASIL, 1995) denomine a atuação do terceiro setor na área social como um processo de publicização, autores que vêm examinando programas de interação do público com o privado no país, mas também no exterior, no campo da educação, têm afirmado que tais movimentos representam diferentes formas de privatização educacional, incidindo sobre gestão das escolas, produção de conteúdo didático e mesmo formação de professores. Nessa perspectiva, é possível afirmar, com Tripodi e Sousa (2018), que os processos de privatização da educação básica no país precisam ser examinados a partir de dois movimentos: a inserção de lógicas de gestão privada na esfera pública e a dispersão da oferta para atores societais.

Adrião (2018), por exemplo, afirma que a privatização da educação tem se efetivado nas dimensões da gestão, com a transferência da gestão escolar para organizações com ou sem fins lucrativos, ou seja, no subsídio com parcerias privadas ou convênios e contratos. Vilela e Donnini (2018), por sua vez, ao analisarem a interação do estado da Paraíba com OS no âmbito dos Ensinos Fundamental, Médio e de Jovens e Adultos, concluem que a "parceria" se voltava a atividades-meio, mais especificamente de apoio escolar.

Para Robertson e Verger (2012), as parcerias público-privadas presentes em vários países constituíram um mercado educacional que não representa a diminuição do Estado, mas sua redefinição em termos de funções no campo da educação. Isso significa que a presença e a atuação do mercado na educação, por meio de parcerias com o privado, com ou sem fins lucrativos, somente se efetivam porque quem o articula e sustenta financeiramente é o próprio Estado.

A lógica de privatização, no campo educacional, que se institui no Brasil, coaduna-se, segundo Sousa e Oliveira (2003), com a ideia de quase-mercado, uma vez que assume a competição como suposta promotora de qualidade, desconsiderando os resultados socialmente desiguais que tais práticas podem induzir.

Essas novas lógicas, que vêm se impondo no campo educacional, expressam, ao que tudo indica, tendências que se encaminham para a consolidação, ainda que apresentem uma trajetória de avanços e recuos, a depender da correlação de forças políticas envolvidas no debate, da presença de movimentos contrarregulatórios e, mais recentemente, da atuação do Judiciário.

O lugar das OS na educação, se examinado em perspectiva histórica, é pedagógico nesse sentido. É possível reconhecê-las, por exemplo, de modo mais frequente, na oferta da educação infantil, especialmente creche. Entretanto, mais recentemente, tem havido um deslocamento para a etapa considerada obrigatória, que vai dos 4 aos 17 anos de idade do estudante, e corresponde, em um sistema de fluxo regular, do pré-escolar ao Ensino Médio. 
Os dados de pesquisa realizada por Silva (2007) sobre a presença do terceiro setor na educação pública do Distrito Federal revelam, por exemplo, que as OSC se fazem presentes também na modalidade de educação especial.

Souza e Flores (2017), por sua vez, ao analisarem o projeto de gestão compartilhada na educação básica de Goiás, sob o prisma do financiamento, afirmam que as OS envolvidas teriam um significativo lucro com a parceria, uma vez que se previam volumosas transferências do ente estadual. Além disso, segundo os autores, os dados sugerem que plano de carreira, contratação por concurso público e valorização via Piso Salarial Nacional dos profissionais da educação poderiam ficar comprometidos com a gestão compartilhada no estado.

A partir de evidências de pesquisa que buscou investigar a parceria entre escolas e OSC, no âmbito da escola integral em Belo Horizonte, Esteffanio (2008) afirma que as suas ações não estavam vinculadas a ações de aprendizagem, mas de assistencialismo.

Já na Bahia, o "Programa Estadual de Organizações Sociais” (BAHIA, 2019) propõe a atuação dessas entidades tanto em atividades-meio quanto naquelas de ensino, como substituição temporária de professores.

Segundo o "Relatório OSCIP e OS", produzido pelo Mapa das Organizações da Sociedade Civil (IPEA, 2020), na área de educação e pesquisa, estão registradas 110 OS, que representam 9,8\% do total de entidades com essa natureza jurídica, conforme se pode ler pela Tabela $2^{1}$.

Tabela 2. Distribuição de Organizações Sociais na área Educação e Pesquisa por etapa e/ou modalidade (2020)

\begin{tabular}{ccc} 
Organizações Sociais & Quantidade & Percentual \\
\hline Educação e Pesquisa (TOTAL) & 110 & $9,8 \%$ \\
\hline Educação Infantil & 55 & $4,94 \%$ \\
\hline Estudos e Pesquisas & 03 & $0,27 \%$ \\
\hline Educação Profissional & 02 & $0,18 \%$ \\
\hline Ensino Médio & 00 & $0,0 \%$ \\
\hline Ensino Fundamental & 02 & $0,18 \%$ \\
\hline Ensino Superior & 03 & $0,27 \%$ \\
\hline Outras formas educação/ensino & 36 & $3,23 \%$ \\
\hline Atividades de apoio à educação & 09 & $0,81 \%$ \\
\hline
\end{tabular}

Fonte: Mapa das Organizações da Sociedade Civil (IPEA, 2020).

Ainda que os limites deste texto não permitam discutir cada um desses dados, cabe sublinhar que o maior número, entre essas 110 OS registradas na área educação, encontra-se na região Sudeste, com 47 entidades, vinte delas atuando na educação infantil, fase creche, principalmente no estado de São Paulo. É também nesse estado, junto com Goiás, que se encontram as duas experiências de OS atuando no Ensino Fundamental, de acordo com os dados. Já a região Sul ocupa a segunda posição no que diz respeito à presença de OS na educação. Das 39 observadas, 34 são voltadas ao atendimento da educação infantil, na fase creche ou pré-escolar, confirmando evidências já documentadas pela literatura, que reconhece a presença do terceiro setor na trajetória de constituição da própria capacidade institucional da creche (CAMPOS, 1998).

Importante considerar que, embora o Sul apareça com um número considerável de OS atuando na educação infantil, o estado do Rio Grande do Sul não possui lei estadual de publicização, pois o Projeto de Lei n.44/2016 fora arquivado em dezembro de 2018. Os entes municipais da região Sul, nesse sentido, avançaram em relação ao estadual na aprovação de legislação atinente. 
O que os dados das OS nos estados brasileiros sugerem, no campo da educação, é que parece haver mesmo um movimento, como apontava Draibe (1993) no início dos anos 1990, em direção a uma reordenação do Estado, o que não pode ser compreendido, por definição, como Estado mínimo, na medida em que ele se mantém forte como um Estado subsidiário. Aliás, é agindo como ator que subsidia a política que esse mesmo Estado constrói as condições necessárias para reordenar suas funções e sustentar a lógica de dispersão de oferta de serviços educacionais.

\section{Resultados e Discussão}

Nesta seção, busca-se construir uma interpretação para o alcance da interação de estados nordestinos com OS, expresso pelos seus marcos legais, fazendo um esforço analítico de projeção das disposições legais observadas para o campo da educação por meio das três categorias construídas a partir da literatura: 1) oferta educacional; 2) gratuidade; e 3) recursos humanos/possibilidade de cessão de servidor público.

\section{Oferta Educacional}

A categoria "Oferta educacional" examina se os marcos legais dos estados, no que diz respeito à interação deles com OS, dispõem sobre a possibilidade de oferta de educação básica por meio desses arranjos. Ou seja, busca-se compreender se os programas de qualificação, aprovados pelos entes estaduais, inseriram a educação básica como uma das áreas sociais passíveis de oferta por essas entidades.

Ao se analisarem os documentos, pode-se observar a ocorrência dessa categoria $1 \mathrm{em}$ todos os estados nordestinos, estando prevista, portanto, a possibilidade de oferta da educação básica nos textos legais dos nove entes estaduais.

A Lei Estadual n. 7.777, do estado de Alagoas, é uma das mais recentes entre os entes federados, tendo sido aprovada em 2016, e prevê, logo no art. 1 $^{\circ}$ que educação, ensino e pesquisa científica podem ser objeto de oferta via OS.

Art. $1^{\circ}$.- O Programa Estadual de Organizações Sociais tem o objetivo de fomentar a absorção, pelas Organizações Sociais constituídas na forma desta Lei, de atividades e serviços de interesse público atinentes à educação, ao ensino, à pesquisa científica, ao desenvolvimento tecnológico e institucional, à proteção e preservação do meio ambiente, bem como à saúde, ao trabalho, à ação social, à cultura $\mathrm{e}$ ao desporto e à agropecuária, tendo como diretrizes básicas [...] (ALAGOAS, 2016).

No estado da Bahia, a Lei estadual n. 8647, de 2003, foi regulamentada pelo Decreto n. 8.890, de 2004, revogando os decretos anteriores n. 7.007 e 7.008, de 1997.

Um primeiro aspecto que se deve levar em conta é que o estado baiano foi um dos primeiros a criar um marco legal de OS, antecedendo mesmo a Lei Federal n. 9.637/1998. Em janeiro de 1997, a Bahia aprovou a Lei Estadual n. 7.027, que instituiu o Programa Estadual de Incentivo às Organizações Sociais. Como a lei federal das OS não havia sido aprovada àquela altura, é possível elucubrar que o estado tenha se valido das ideias e diretrizes contidas no PDRAE para produzir sua normativa.

As premissas que sustentavam a reforma gerencial do Estado podem ser lidas já no art. $1^{\circ}$ da Lei n. 7.029/1997 e nos seus incisos, bem como a inserção de ensino e pesquisa como possibilidades de oferta por OS: 
Art. $1^{\circ}$. Fica instituído o Programa Estadual de Incentivo às Organizações Sociais, com o objetivo de fomentar a absorção de atividades que, por força de previsão constitucional, já venham sendo exercidas também pelo setor privado, tais como ensino, pesquisa científica e tecnológica, cultura, saúde ou outras, pelas Organizações Sociais, constituídas na forma desta Lei, observadas as seguintes diretrizes:

I - adoção de critérios que assegurem a otimização do padrão de qualidade na execução dos serviços e no atendimento ao cidadão;

II - promoção de meios que favoreçam efetiva redução de formalidades burocráticas para o acesso aos serviços;

III - adoção de mecanismos que possibilitem a interação, entre os setores públicos do Estado, a sociedade e o setor privado (BAHIA, 1997).

Note-se que estão claros os pressupostos do PDRAE nos seus dois aspectos centrais: redução de formalidade burocrática, sugerindo, para tanto, a sua substituição pelo modelo gerencial, e interação do Estado com a sociedade, expressa, no caso em questão, pelas Organizações Sociais. Ainda fortemente vinculada ao marco conceitual está a possibilidade de absorção, pelas OS, de atividades realizadas pelo Estado, a busca por modelos gerenciais flexíveis e o controle por resultados e melhoria da eficiência econômica.

Essa lei foi revogada pela Lei Estadual n. 8.647, de 2003, que, por sua vez, fora regulamentada pelo Decreto n. 8.890, de 2004. Quanto à possibilidade de oferta educacional por meio de OS, é possível afirmar que os três textos legais preveem tal situação, pois não houve alteração no art. 1/] em nenhuma das versões das leis.

A Lei Estadual do Ceará, n. 12.781/1997, obedece à mesma lógica do estado da Bahia, tendo sido aprovada antes mesmo da lei federal. Nesse estado, não aparece a possibilidade de oferta de pesquisa, mantendo-se termo "educação".

Art. $1^{\circ}$. O Poder Executivo poderá, mediante Decreto, qualificar como Organizações Sociais, pessoas jurídicas de direito privado, sem fins lucrativos, cujas atividades sejam dirigidas à assistência social, à saúde, ao trabalho, à educação, à cultura, ao turismo, à gestão ambiental, à habitação, à ciência e tecnologia, à agricultura, à organização agrária, ao urbanismo, ao saneamento, ao desporto e lazer, com o objetivo de fomentar a descentralização de atividades e serviços públicos não exclusivos desempenhados por órgãos ou entidades públicas estaduais, observadas as seguintes diretrizes [...] (CEARÁ, 1997).

No Maranhão, a lei estadual nasce antes da federal, embora no mesmo ano, 1998. É um texto mais sucinto, não apresentando premissas ou diretrizes gerenciais vinculadas à oferta educacional por OS, ainda que a Lei n. 7.066 disponha, no art. $1^{\circ}$, sobre a possiblidade de oferta de ensino, pesquisa científica e desenvolvimento tecnológico:

Art. $1^{\circ}$. O Poder Executivo poderá qualificar como Organizações Sociais pessoas jurídicas de direito privado, sem fins lucrativos, cujas atividades sejam dirigidas ao ensino, à pesquisa científica e desenvolvimento tecnológico, à proteção e preservação do meio ambiente e à saúde, atendidos os requisitos previstos nesta Lei (MARANHÃO, 1998). 
No estado da Paraíba, a Lei n. 9.654, de outubro de 2011, institui o programa de gestão pactuada com OS, visando à atuação conjunta. A lei estadual prevê os mesmos mecanismos de atuação, fiscalização e qualificação de que dispunha a Lei Federal n. 9.637, de 1998. Ao contrário de outros estados até agora examinados, o estado da Paraíba não explicita, no seu texto legal, quais as políticas sociais que serão objeto de parceria, apenas indicando que seriam aquelas que constituem o que o PDRAE denominou atividades não exclusivas do Estado; ou seja, ensino, pesquisa cientifica e tecnológica, conforme se pode observar do art. $1^{\circ}$ da Lei n. 9.454/2011.

Art.1 ${ }^{\circ}$. Fica instituído, no estado da Paraíba, o Programa Gestão Pactuada, visando a disciplinar a atuação conjunta dos órgãos e entidades públicas, das entidades qualificadas como Organização Social e entidades privadas, na realização de atividades públicas não exclusivas, mediante o estabelecimento de critérios para sua atuação, qualificação e mecanismos de coordenação, fiscalização e controle das atividades delegadas, nos termos da Lei Federal n. 9.637, de maio de 1998, e da Lei Complementar Estadual n. 74, de 16 de março de 2007 (PARAÍBA, 2011).

Quanto às diretrizes defendidas, já o parágrafo único do art. $1^{\circ}$ consagra os mesmos fundamentos colocados no PDRAE: autonomia financeira, flexibilidade de gestão, integração de sociedade civil organizada, redesenho de atuação no Estado, uso de modelos gerenciais, controle por resultados e redução de custos.

A legislação de Pernambuco sobre a interação do Estado com entidades da sociedade civil contempla três arranjos legais: a lei originalmente formulada no ano de 2000, n. 11.743, alterada em 2005 pela Lei n. 12.973 e, mais recentemente, em 2010, pela Lei n. 14.248 .

O primeiro aspecto que se deve considerar no estado de Pernambuco é o fato de que uma mesma lei regule parcerias do Estado tanto com OS quanto com OSCIP, embora o padrão relacional entre essas duas formas de interação tenha efeitos bastante diferentes sobre as políticas.

A Lei n. 11.743/2000 prevê, no seu art. $1^{\circ}$, a prestação de atividades não exclusivas do Estado pelas OS.

Art. $1^{\circ}$. Fica instituído o Sistema Integrado de Prestação de Atividades Públicas Não Exclusivas, com a finalidade de disciplinar a atuação conjunta dos órgãos e entidades públicas, das entidades qualificadas como Organização Social ou como Organização da Sociedade Civil de Interesse Público, e das entidades privadas, na realização de atividades públicas não exclusivas, mediante o estabelecimento de critérios para sua atuação, qualificação ou credenciamento e de mecanismos de coordenação, fiscalização e controle das atividades delegadas (PERNAMBUCO, 2000).

Nota-se que a especificação da modalidade de educação profissional é trazida no corpo da lei apenas desse ente federado. De igual modo, apenas na lei de Pernambuco foi disposta a criação de um Sistema Integrado de Prestação de Atividades Públicas Não Exclusivas, cujo objetivo seria assegurar a prestação de serviços com autonomia administrativa e financeira e controle de resultados, garantir o acesso aos serviços de maneira simplificada, modelos gerenciais flexíveis, controle por resultados e redução de custos.

A Lei Ordinária n. 5.519, de dezembro de 2005, do Piauí, prevê a absorção de políticas sociais como ensino, pesquisa cientifica e tecnológica por OS, ficando explicitado que os serviços de natureza social, passíveis de ser ofertados pela iniciativa privada, podem ser absorvidos pelas OS qualificadas.

Art. $1^{\circ}$. O Poder Executivo, após autorização prévia do Poder Legislativo, poderá autorizar a absorção de atividades e serviços que, por força de previsão constitucional, já venham sendo exercidos também pelo setor privado, tais como ensino, pesquisa cientifica e tecnológica, 
proteção e preservação do meio ambiente, cultura, saúde, por Organizações Sociais, constituídas na forma desta Lei, observadas as seguintes diretrizes [...] (PIAUÍ, 2005).

No estado do Rio Grande do Norte, a Lei Complementar n. 271/2004 foi alterada e acrescida pela Lei Complementar n. 468/2012. Na primeira versão, estavam previstas somente atividades voltadas ao ensino de turismo e hotelaria. Já na LC n. 468/2012, o art. $1^{\circ}$ foi alterado e foi acrescida a possibilidade de que as atividades fossem dirigidas ao ensino, à pesquisa científica, ao desenvolvimento tecnológico, à cultura, à saúde e ao meio ambiente, havendo, assim, uma alteração significativa de curso profissionalizante para a atuação de OS na educação de modo geral:

Art. $1^{\circ}$. O Poder Executivo, por ato do Governador do Estado, poderá qualificar como organizações sociais pessoas jurídicas de direito privado, sem fins econômicos, cujas atividades sejam dirigidas ao ensino, à pesquisa científica, ao desenvolvimento tecnológico, à proteção e à preservação do meio ambiente, à cultura e à saúde, atendidos os requisitos previstos nesta Lei Complementar (RIO GRANDE DO NORTE, 2012).

O marco legal do estado de Sergipe foi inicialmente aprovado pela Lei n. 5.217, de 15 de dezembro de 2003, sendo posteriormente alterado pela Lei n. 5.285/2004. Nele, estava presente a possibilidade de OS atuarem tanto no ensino quanto na pesquisa:

Art. $1^{\circ}$. O Poder Executivo estadual pode qualificar, como Organização Social, pessoas jurídicas de direito privado, sem fins lucrativos, cujas atividades sejam dirigidas ao ensino, à pesquisa e ao desenvolvimento tecnológico, abrangendo, também, as áreas de cultura, preservação do meio ambiente, saúde, assistência social e desporto, desde que os objetivos sociais e as disposições estatutárias da respectiva entidade atendam aos requisitos estabelecidos por esta Lei (SERGIPE, 2003).

Ao se cotejar o art. $1^{\circ}$ da lei de 2003 com a alteração proposta na lei de 2004, chama-se a atenção para a possibilidade de o mesmo marco legal regular ainda as relações do Estado com OSCIP e, ainda mais, outras formas de convênio e terceirização.

\section{Gratuidade da Educação}

Buscou-se investigar se os textos legais explicitam a gratuidade da oferta educacional, ou ao menos sugerem que essa definição seja inserida no contrato de gestão a ser firmado entre Estado e OS. Em estreito alinhamento ao texto legal federal, a quase totalidade dos estados não explicitou em seus documentos, que propõem programas de qualificação para atuarem em áreas sociais, como a educação seria ofertada, se gratuita ou não. De igual modo, não se indicou que tal disposição deveria se tornar cláusula a ser trazida nos contratos de gestão. Apenas o estado de Pernambuco cuidou de explicitar em sua lei que as OS promoveriam educação gratuita.

Essa é uma questão importante, haja vista que um dos argumentos fortes do PDRAE é que a existência da propriedade pública não estatal não significaria privatização, uma vez que o "cidadão-cliente" não pagaria pelos serviços ofertados. Contudo, os valores liberais que circundam o New Public Management defendem que o Estado deva garantir a gratuidade apenas para a educação considerada "elementar" (FRIEDMAN,2016), considerando um excesso estatal a oferta de algumas modalidades educacionais, como ensino profissional, por exemplo. 


\section{Possibilidade de Transferência de Servidores para OS}

A possibilidade de servidores públicos serem transferidos para OS parece ser um dos pontos mais polêmicos da lei federal, mas, ao mesmo tempo, pode-se dizer que é um dos elementos de maior "apelo" da proposta, a depender de como se efetiva a transferência do servidor. O que se quer dizer aqui é que a discussão em torno do peso da folha de pagamento, do plano de carreira e dos salários e, especialmente, da previdência social tem se tornado o centro do debate fiscal dos entes subnacionais, uma vez que parte deles já atingiu o teto da Lei de Responsabilidade Fiscal.

Nesse sentido, as OS poderiam constituir atrativa ferramenta para os governos lidarem com a questão fiscal, como as folhas de pagamento de professores, na medida em que tais encargos não mais estariam sob responsabilidade estatal.

Um dos primeiros elementos que chamam a atenção na análise da categoria 3, que investiga a possibilidade de transferência de servidores para as OS, diz respeito à sua ocorrência; ou seja, nos nove marcos legais estaduais, há regramento sobre essa questão.

No caso do estado de Alagoas, a Lei n. 7.777, de 22 de janeiro de 2016, no art. 34, dispõe que os servidores estaduais poderão ser colocados à disposição das OS, mas disciplina, no art. 35, a possibilidade de o servidor manter seu vínculo com o Estado, em caso de ser colocado à disposição das OS.

Art. 35. O ato de disposição pressupõe aquiescência do servidor, hipótese em que ficará mantido seu vínculo com o Estado, [...] computando-se o tempo de serviço prestado para todos os efeitos legais, inclusive promoção por antiguidade e aposentadoria, [que] está vinculada ao desconto previdenciário próprio dos servidores públicos do Estado (ALAGOAS, 2016).

Entretanto, se a princípio parece haver a garantia de escolha do servidor, ela pode ser entendida mais como uma escolha regulada, na medida em que, uma vez não se aceitando a transferência, ele pode ser redistribuído com o mesmo cargo, embora com a possibilidade de mudança de sede, de órgão ou entidade do mesmo poder. Pode, ainda, ser colocado em disponibilidade, com remuneração proporcional ao tempo de serviço, até que seja instituído seu aproveitamento na administração, uma vez constatada a impossibilidade de sua redistribuição.

Já em relação a aspectos fiscais, prevê-se, no art. 37, a não incorporação de eventuais gratificações recebidas no âmbito da OS. O art. 39, por sua vez, dispõe que, embora o estado continue recolhendo a previdência de seus funcionários, inclusive os que atuam nas OS, esse valor recolhido precisa ser descontado no orçamento destinado a essas organizações. Ou seja, no caso específico de Alagoas, o marco legal tenta equacionar um problema fiscal, que é o gasto previdenciário, por meio de sua transferência às OS, de modo indireto, como se pode ler pela transcrição do art. 39: "O valor pago pelo Estado, a título de remuneração e de contribuição previdenciária do servidor colocado à disposição da Organização Social, será abatido do valor de cada repasse mensal" (ALAGOAS, 2016).

No caso da Bahia, o Decreto n. 8.890, de 2004, normatiza a possibilidade de se colocar à disposição de OS os servidores estaduais titulares de cargo efetivo (art. 35). Obedecendo à mesma lógica do estado de Alagoas, o decreto prevê a "aceitação" do servidor, mantendo a contagem de tempo para a aposentadoria, bem como o desconto previdenciário sob responsabilidade estatal (art. 36).

Já o art. 38 dispõe sobre a possibilidade de cancelamento de disposição do servidor. À diferença do estado de Alagoas, aqui, o texto prevê a solicitação de encerramento da disposição, tanto pelo servidor, quanto pela OS. Do ponto de vista previdenciário, estabelece, no seu art. 39, que, embora a contribuição se 
mantenha sob responsabilidade do Estado em termos de recolhimento, o valor destinado a esse fim deverá ser subtraído do orçamento destinado às entidades.

A legislação estadual do Ceará vai no sentido contrário às demais da região no tocante a essa categoria. Embora o estado se alinhe às ideias e premissas gerenciais defendidas pelo PDRAE, como utilização de contratos de gestão, criação de estrutura de incentivos e foco na eficiência econômica, o marco legal cearense veda a possibilidade de servidor público ser transferido para OS, independentemente de haver ou não ônus para o estado:

Art. 15. É vedada a cessão de servidores da administração pública direta autárquica e fundacional do Estado de qualquer dos poderes, bem como de empregados das empresas públicas e sociedades de economia mista do Estado, com ou sem ônus para o órgão ou entidade de origem, para servirem ou trabalharem nas Organizações Sociais de que trata esta Lei (CEARÁ, 1997).

O texto legal do Maranhão é bastante lacônico no que diz respeito ao regramento de servidores e à possibilidade de serem absorvidos. Ele se restringe a facultar a cessão e a incorporação de vantagens pecuniárias. No art. 14, por exemplo, positiva-se como possível a cedência, embora o ônus dessa escolha recaia sobre o Estado que cedeu: "Art. 14. Fica facultada ao Poder Executivo a cessão especial de servidor para as Organizações Sociais, com ônus para o órgão ou entidade cedente” (MARANHÃO, 1998). Já os $\$ \$ 1^{\circ}$ e $2^{\circ}$ dispõem sobre incorporações a salário. O Maranhão não permite a incorporação de vantagem pecuniária que porventura tenha pago a servidor cedido, bem como não se admite que sejam utilizados recursos provenientes do contrato de gestão para pagamento de tais vantagens.

O art. 24 da Lei n. 9.454, de 2011, da Paraíba, equipara-se aos estados de AL, BA e PE, tanto na possibilidade de transferência do servidor para as OS quanto nas condicionalidades de sua permanência no serviço público. Assim, positiva-se que os servidores uma vez transferidos passem a seguir as normas estabelecidas pelas OS. No art. 25, é assegurado ao servidor a possibilidade de solicitar o cancelamento de sua cessão. Uma vez efetivada, o art. 26 dispõe que vantagens porventura pagas ao servidor não poderão ser incorporadas ao salário de origem. Na lei paraibana é possibilitada a migração do servidor em caso de ser titular de dois cargos e quando não exista incompatibilidade de horários. A Paraíba também normatiza $\mathrm{o}$ abatimento no repasse direcionado a OS do valor pago à previdência do servidor cedido, conforme o art. 28 (PARAÍBA, 2011).

Em Pernambuco, no art. 31 da Lei n. 11.743, de 2000, alterado pela Lei n. 12.973, de 2005, estava positivado um período definido de dois anos, prorrogável por mais dois, para que o servidor pudesse ficar em cessão. Na primeira alteração do marco legal, o regramento para disponibilização de servidor estava condicionado ao seu desligamento temporário, fosse por licença, fosse por suspensão de contrato de trabalho, durante o período de transferência. Desejando o servidor permanecer na OS após o período de cessão, o texto dispõe sobre a compulsoriedade de rompimento de vínculo pregresso em caráter definitivo. Outro aspecto que recebe nova redação diz respeito à estrutura de incentivos passível de ser ofertada ao servidor cedido, desde que o valor seja originário de recursos próprios da OS.

Em 2010, a Lei n. 11.743/2000 voltou a ser alterada, prevendo a dispensa de obrigatoriedade de abertura de processo de afastamento funcional para atuar nas OS, deixando a cargo da administração pública a discricionariedade do ato, embora seja dada ao servidor a possibilidade de consentir ou não com a cessão. Também nesse caso, há uma condição de escolha regulada, visto que ao servidor, uma vez recusando a disponibilidade, fica com salário proporcional ou pode mudar de sede ou órgão. A diferença observada 
em relação aos estados citados é que, no caso de Pernambuco, a questão previdenciária não é contabilizada a favor do Estado, na medida em que a legislação não prevê o desconto do recolhimento de previdência do servidor cedido no repasse de orçamento à OS.

No estado do Piauí, a Lei Ordinária n. 5.519, de 2005, no seu artigo 17 e parágrafos, regra juridicamente a política de recursos humanos do âmbito das OS, permitindo a cessão de servidores, mas determinando o ônus para o Estado. Seguindo a mesma direção de outros estados aqui analisados, o Piauí prevê a impossibilidade de incorporação ao salário do servidor qualquer bonificação ou acréscimo que vier a ser pago pela OS. Também a lei veta a possibilidade de se utilizarem recursos destinados ao cumprimento dos contratos de gestão para pagamento de vantagem a servidor cedido, exceto em cargos de direção.

No Rio Grande do Norte, o texto legal, no seu art. 17, reproduz o documento piauiense, normatizando a cessão de servidores e permitindo o recebimento de vantagens, desde que não provenientes de recursos destinados à execução de contratos de gestão, também proibindo a incorporação de vantagens pagos por OS aos salários de origem.

No marco legal de Sergipe, a possibilidade de cessão de servidor público está posta no inciso VII do art. $5^{\circ}$ da Lei n. 5.217/2003, bem como no parágrafo único e seus incisos, prevendo a cessão, embora podendo ser revista, em caso de requerimento por parte do interessado. A lei estadual também normatiza a impossibilidade de se pagarem vantagens como bonificação, com recursos destinados a cumprir metas do contrato de gestão. De igual modo, fica vetada a possibilidade de se incorporar ao estipêndio do servidor qualquer vantagem que porventura tenha sido recebida por ele, da Organização Social, configurando apenas como um subsídio.

\section{Considerações Finais}

O artigo apresenta resultado de pesquisa sobre o alcance de OS na educação básica, expresso em marcos legais de estados do Nordeste. Embora seja possível afirmar que a presença de diferentes entidades do terceiro setor na oferta educacional já venha sendo observada e documentada pelas pesquisas da área, é importante sublinhar que sua atuação esteve circunscrita até recentemente à educação infantil, especialmente nas creches. Contudo, tem-se observado iniciativas em direção à atuação também na etapa considerada obrigatória da educação.

Os resultados permitem afirmar que os marcos legais de todos os estados do Nordeste alcançam a educação básica na possibilidade de oferta, mas também na carreira docente, tendo em vista a possibilidade de se ceder servidor público para as OS.

Quando se trata, no entanto, do modo de oferta, se gratuita ou paga, apenas Pernambuco explicita a gratuidade; todos os demais estados silenciam sobre a temática, bastante cara aliás aos defensores do liberalismo econômico, cuja crença é baseada na compreensão de que apenas a etapa considerada básica deve ser provida de forma gratuita, excluídas, nesse caso, modalidades como ensino profissional.

No que se refere à possibilidade de se ceder servidor público para atuar em OS, com exceção do Ceará, todos os entes analisados preveem a cessão, mas, também, o retorno do servidor ao setor estatal. Todavia, os dados permitem afirmar que esse princípio de escolha, que se encontra resguardado na legislação estadual, está condicionado a um conjunto de fatores. O retorno poderá se dar, por exemplo, com mudança de sede ou de órgão, a depender do interesse da administração. Ademais, na impossibilidade de redistribuição ou na hipótese de extinção do cargo, o servidor será posto em disponibilidade, fazendo jus à remuneração proporcional ao respectivo tempo de serviço, até que seja efetivado seu regular aproveitamento. Ainda no âmbito da cessão, 
a pesquisa traz elementos necessários à afirmação de que os entes subnacionais podem utilizar o desenho de interação do Estado com as OS como ferramenta para reduzir o impacto da previdência dos servidores. Isso porque, ao se efetivar a cessão, embora a contribuição previdenciária continue a ser praticada pelo órgão de origem, os valores relativos a essa arrecadação são descontados do orçamento destinado às OS, portanto caberá a elas arcar com essa rubrica, que está longe de ser considerada irrisória no cômputo geral da despesa pública.

\section{Contribuições das Autoras}

Problematização e Conceituação: Silva A, Tripodi ZF; Metodologia: Silva A, Tripodi ZF; Análise: Silva A, Tripodi ZF; Redação: Silva A, Tripodi ZF.

\section{Notas}

1. Ao utilizarmos bancos de dados de OS, é necessário parcimônia nas generalizações, pois a qualificação dessas entidades é de prerrogativa do Executivo, independentemente da esfera. Assim, muitas entidades podem receber a qualificação, mas, como não há um cadastro nacional obrigatório para se inserirem os dados de OS qualificadas, conta-se apenas com aqueles disponíveis, o que impõe limites às pesquisas realizadas.

\section{Referências}

ADRIÃO, T. Dimensões e formas da privatização da educação no brasil: caracterização a partir de mapeamento de produções nacionais e internacionais. Currículo sem Fronteiras, Braga, v. 18, n. 1, p. 8-28, jan./abr. 2018.

ALAGOAS. Lei n. 7.777, de 22 de janeiro de 2016. Dispõe sobre o Programa Estadual de Organizações Sociais e dá outras providências. Maceió: Assembleia Legislativa de Alagoas, 2016.

AVRITZER, L. Sociedade civil e Estado no Brasil: da autonomia à interdependência política. Opinião Pública, Campinas, v. 18, p. 383-398, 2012. https://doi.org/10.1590/S0104-62762012000200006

BAHIA. Lei n. 7.027, de 29 de janeiro de 1997. Institui o Programa Estadual de Incentivo às Organizações Sociais e dá outras providências. Salvador: Governo do Estado da Bahia, 1997.

BAHIA. Lei n. 8.647, de 29 de julho de 2003. Dispõe sobre o Programa Estadual de Organizações Sociais e dá outras providências. Salvador: Governo do Estado da Bahia, 2003.

BAHIA. Programa Estadual de Organizações Sociais. Salvador: Governo do Estado da Bahia, 2019.

BRASIL. Plano Diretor da Reforma do Aparelho do Estado. Brasília, DF: Presidência da República, Brasília: 1995.

BRASIL. Presidência da República. Lei n. 9.637/1998, de 15 de maio de 1998. Dispõe sobre a qualificação de entidades como organizações sociais, a criação do Programa Nacional de Publicização, a extinção dos órgãos e entidades que menciona e a absorção de suas atividades por organizações sociais, e dá outras providências.

Diário Oficial da União, Brasília, DF, 1998. 
BRASIL. Cadernos do MARE. Brasília, DF: Ministério da Administração Federal e Reforma do Estado, 1998.

BRESSER-PEREIRA, L. C.; GRAU, N. C. Entre o Estado e o Mercado: o público não-estatal. In: BRESSERPEREIRA, L. C.; GRAU, N. C. (orgs.). O público não estatal na reforma do Estado. Rio de Janeiro: Editora FGV, 1999. p. 15-48.

CAMPOS, M. M. A regulação da educação infantil. In: BRASIL. Subsídios para credenciamento e funcionamento de instituições de educação infantil. Brasília, DF: MEC, 1998. v. II.

CEARÁ. Lei n. 12.781, de 30 de dezembro de 1997. Institui o Programa Estadual de Incentivo às Organizações Sociais, dispõe sobre a qualificação destas entidades e dá outras providências. Fortaleza: Assembleia Legislativa do Estado do Ceará, 1997.

DALE, R. A promoção do mercado educacional e a polarização da educação. Educação, Sociedade e Culturas, Porto, n. 12, p. 109-139, 1994.

DI PIETRO, M. S. Z. Parcerias na administração pública: concessão. permissão, franquia, terceirização, parceria público-privada e outras formas. São Paulo: Atlas, 2015.

DONNINI, T. O alcance da Lei Federal de organizações Sociais (Lei n. 9.637/98). Revista Brasileira de Direito Público, Belo Horizonte, ano 15, n. 59, p. 35-45, out./dez. 2017.

DRAIBE, S. M. O Welfare State no Brasil: características e perspectivas. Caderno, NEPP/UNICAMP, n. 8, 1993.

ESTEFFANIO, M. B. As organizações da sociedade civil de Belo Horizonte em parceria com a escola: reproduções, confrontes e convergências. 2008. 289 f. Dissertação (Mestrado em Educação) - Faculdade de Educação, Universidade Federal de Minas Gerais, Belo Horizonte, 2008.

FRIEDMAN, M. O papel do governo na educação. Capitalismo e Liberdade. Rio de Janeiro: LTC, 2016.

GOBETTI, S. W; ORAIR, R. O. Progressividade tributária: a agenda negligenciada. Texto para Discussão n. 2190. Brasília, DF/Rio de Janeiro: Ipea, 2016.

GOHN, M. G. 500 anos de lutas sociais no Brasil: movimentos sociais, ONGs e terceiro setor. Mediações Revista de Ciências Sociais, Londrina, v. 5, n. 1, p. 11-40, 2000. https:// doi.org/10.5433/2176-6665.2000v5n1p11

IFDM [ÍNDICE FIRJAN DE DESENVOLVIMENTO MUNICIPAL]. Índice Firjan de Gestão Fiscal. [S. 1.]: Firjan, 2017. Disponível em: https://www.firjan.com.br/ifgf/consulta-ao-indice/. Acesso em: 25 jul. 2020.

IPEA [INSTITUTO DE PESQUISA ECONÔMICA APLICADA]. Relatório OSCIP e OS. Perfil das Organização Social e Organização da Sociedade Civil de Interesse Público em atividade no Brasil. Brasília, DF/Rio de Janeiro: Ipea, 2020.

LAVALLE, A. G.; SZWAKO, J. Sociedade civil, Estado e autonomia: argumentos, contra-argumentos e avanços no debate. Opinião Pública, Campinas, v. 21, n. 1, p. 157-187, 2015. https://doi.org/10.1590/1807-0191211157

MARANHÃO. Lei n. 7.066, de 03 de fevereiro de 1998. Dispõe sobre a qualificação das entidades como Organizações Sociais e dá outras providências. São Luiz: Procuradoria Geral do Estado do Maranhão, 1998.

MODESTO, P. Reforma do Marco Legal do Terceiro Setor no Brasil. Revista de Direito Administrativo, 
Rio de Janeiro, v. 214, p. 55-68, out./dez. 1998. https://doi.org/10.12660/rda.v214.1998.47266

OLIVEIRA, R. P.; ADRIÃO, T. Os 25 anos da Constituição de 1988: reflexões sobre o direito à educação de qualidade. In: LEITE, Y.; MILITÃO, S.; LIMA, V. Políticas educacionais e qualidade da educação pública. Curitiba: CRV, 2013. p. 29-42.

PARAÍBA. Lei n. 9.454, de 06 de outubro de 2011. Institui o Programa de Gestão Pactuada, dispõe sobre a qualificação de Organizações Sociais e dá outras providências. João Pessoa: Assembleia Legislativa do Estado da Paraíba, 2011.

PERNAMBUCO. Lei n. 11.743, de 20 de janeiro de 2000. Sistematiza a prestação de serviços públicos não exclusivos, dispõe sobre a qualificação de Organizações Sociais e da Sociedade Civil de interesse público e o fomento às atividades sociais, e dá outras providências. Recife: Assembleia Legislativa do Estado de Pernambuco, 2000.

PIAUÍ. Lei n. 5.519, de 13 de dezembro de 2005. Dispõe sobre a qualificação de entidades como Organizações Sociais, e dá outras providências. Teresina: Assembleia Legislativa do Estado do Piauí, 2005.

RIO GRANDE DO NORTE. Lei Complementar n. 271, de 26 de fevereiro de 2004. Dispõe sobre a qualificação de entidades como organizações sociais, a criação do Programa Estadual de Publicização, e dá outras providências. Natal: Assembleia Legislativa do Estado do Rio Grande do Norte, 2004.

RIO GRANDE DO NORTE. Lei Complementar n. 271, de 22 de junho de 2012. Altera a redação e acresce dispositivo à Lei Complementar Estadual n. 271, de 26 de fevereiro de 2012. Natal: Assembleia Legislativa do Estado do Rio Grande do Norte, 2012.

ROBERTSON, S.; VERGER, A. A origem das parcerias público-privada na governança global da educação. Educação \& Sociedade, Campinas, v. 33, n.121, p. 1133-1156, 2012. https://doi.org/10.1590/ S0101-73302012000400012

SERGIPE. Lei n. 5.217, de 15 de dezembro de 2003. Dispõe sobre a qualificação de entidades como Organização Social e sua vinculação contratual com o Poder Público Estadual, e dá providências correlatas. Aracaju: Assembleia Legislativa do Estado do Sergipe, 2003.

SOUSA, S. Z. L.; OLIVEIRA, R. P. Políticas de avaliação da educação e quase mercado no Brasil.

Educação \& Sociedade, Campinas, v. 24, n. 84, p. 873-895, set. 2003. https://doi.org/10.1590/ S0101-73302003000300007

SOUZA, F. A.; FLORES, M. M. L. Uma análise sobre a implementação das Organizações Sociais nas escolas de Goiás: os recursos públicos em questão. Revista Eletrônica de Educação, São Carlos, v. 11, n. 1, p. 217-229, jan./maio 2017. https://doi.org/10.14244/198271991604

STUCHI, C. G. et al. Velhas tendências, novos arranjos: a autonomia universitária frente às propostas de Organizações Sociais e Fundos Patrimoniais. Jornal de Políticas Educacionais. Curitiba, v. 14, n. 13. jan. 2020. https:// doi.org/10.5380/jpe.v14i0.70090

VILELLA, M.; DONNINI, T. L. F. Organizações sociais na educação: contexto histórico e legislativo e análise de uma experiência em fase de implementação. Revista de Direito do Terceiro Setor. Belo Horizonte, v. 12, n. 24, p. 29-59, jul./dez. 2018. 
TRIPODI, Z. F.; SOUSA, S. Z. Do governo à governança: permeabilidade do estado a lógicas privatizantes na educação. Cadernos de Pesquisa, São Paulo, v. 48, n. 167, p. 228-253, mar. 2018. https://doi. org/10.1590/198053144800

\section{Sobre as Autoras}

Ariane Silva é licenciada em História pela Universidade Federal de Viçosa (UFV) e mestra em Educação pela Universidade Federal de Ouro Preto (UFOP). Integra o Núcleo de Estudos e Pesquisas em Políticas Públicas de Educação - NEPPPE/CNPq.

Zara Figueiredo Tripodi é professora do Departamento de Educação e do Programa de Pós-graduação em Educação. Pesquisadora da Universidade de Federal Ouro Preto (UFOP) e coordenadora do Núcleo de Estudos e Pesquisas em Políticas Públicas de Educação - NEPPPE/CNPq. Doutora em Educação pela Universidade de São Paulo (USP).

Recebido: 31 jul. 2020

Aprovado: 15 out. 2020 